\title{
Fisher linear discriminant analysis for classification and prediction of genomic susceptibility to stomach and colorectal cancers based on six STR loci in a northern Chinese Han population
}

\author{
Shuhong Hao ${ }^{1}$, Ming Ren ${ }^{2}$, Dong Li $^{3}$, Yujie Sui ${ }^{4}$, Qingyu Wang $^{2}$, Gaoyang Chen $^{2}$, Zhaoyan Li $^{2}$, Qiwei Yang $^{\text {Corresp. } 4}$ \\ 1 Department of Hematology and Oncology, The Second Hospital of Jilin University, Changchun, Jilin Province, China \\ 2 Department of Orthopedics, , The Second Hospital of Jilin University, Changchun, Jilin Province, China \\ 3 Department of Obstetrics and Gynecology, The Second Hospital of Jilin University, Changchun, Jilin Province, China \\ 4 Medical Research Center, The Second Hospital of Jilin University, Changchun, Jilin Province, China \\ Corresponding Author: Qiwei Yang \\ Email address: qiweiy@163.com
}

Objective. Gastrointestinal cancer is the leading cause of cancer-related death worldwide. The aim of this study was to verify whether the genotype of six short tandem repeat (STR) loci including AR, Bat-25, D5S346, ER1, ER2, and FGA is associated with the risk of gastric cancer (GC) and colorectal cancer (CRC) and to develop a model that allows early diagnosis and prediction of inherited genomic susceptibility to GC and CRC.

Methods. Alleles of six STR loci were determined using the peripheral blood of six colon cancer patients, five rectal cancer patients, eight GC patients, and 30 healthy controls. Fisher linear discriminant analysis (FDA) was used to establish the discriminant formula to distinguish GC and CRC patients from healthy controls. Leave-one-out cross validation and receiver operating characteristic (ROC) curves were used to validate the accuracy of the formula. The relationship between the STR status and immunohistochemical (IHC) and tumor markers was analyzed using multiple correspondence analysis.

Results. D5S346 was confirmed as a GC- and CRC-related STR locus. For the first time, we established a discriminant formula on the basis of the six STR loci, which was used to estimate the risk coefficient of suffering from GC and CRC. The model was statistically significant (Wilks' lambda $=0.471, \chi 2=30.488$, $\mathrm{df}=13$, and $\mathrm{p}=0.004)$. The results of leave-one-out cross validation showed that the sensitivity of the formula was $73.7 \%$ and the specificity was $76.7 \%$. The area under the ROC curve (AUC) was 0.926 , with a sensitivity of $73.7 \%$ and a specificity of $93.3 \%$. The STR status was shown to have a certain relationship with the expression of some IHC markers and the level of some tumor markers.

Conclusions. The results of this study complement clinical diagnostic criteria and present markers for early prediction of GC and CRC. This approach will aid in improving risk awareness of susceptible individuals and contribute to reducing the incidence of GC and CRC by prevention and early detection. 


\section{Fisher linear discriminant analysis for classification}

2 and prediction of genomic susceptibility to stomach

3 and colorectal cancers based on six STR loci in a

4 northern Chinese Han population

5

6

7
Shuhong $\mathrm{Hao}^{1}$, Ming $\mathrm{Ren}^{2}$, Dong $\mathrm{Li}^{3}$, Yujie $\mathrm{Sui}^{4}$, Qingyu Wang², Gaoyang $\mathrm{Chen}^{2}$, Zhaoyan $\mathrm{Li}^{2}$, Qiwei Yang ${ }^{4 *}$

${ }^{1}$ Department of Hematology and Oncology, The Second Hospital of Jilin University, Changchun, Jilin, China

${ }^{2}$ Department of Orthopedics, The Second Hospital of Jilin University, Changchun, Jilin, China

${ }^{3}$ Department of Obstetrics and Gynecology, The Second Hospital of Jilin University, Changchun, Jilin, China

${ }^{4}$ Medical Research Center, The Second Hospital of Jilin University, Changchun, Jilin, China

*Corresponding Author:

Qiwei Yang, Ph.D.

Ziqiang Street No.265, Changchun, Jilin, 130041, China.

Email address: qiweiy@163.com 
38

39

40

41

42

43

44

45

46

47

48

49

50

51

52

53

54

55

56

57

58

59

60

61

62

63

64

65

66

67

68

69

70

71

72

73

74

75

76

77

\section{Abstract}

Objective. Gastrointestinal cancer is the leading cause of cancer-related death worldwide. The aim of this study was to verify whether the genotype of six short tandem repeat (STR) loci including AR, Bat-25, D5S346, ER1, ER2, and FGA is associated with the risk of gastric cancer (GC) and colorectal cancer (CRC) and to develop a model that allows early diagnosis and prediction of inherited genomic susceptibility to GC and CRC.

Methods. Alleles of six STR loci were determined using the peripheral blood of six colon cancer patients, five rectal cancer patients, eight GC patients, and 30 healthy controls. Fisher linear discriminant analysis (FDA) was used to establish the discriminant formula to distinguish GC and $\mathrm{CRC}$ patients from healthy controls. Leave-one-out cross validation and receiver operating characteristic (ROC) curves were used to validate the accuracy of the formula. The relationship between the STR status and immunohistochemical (IHC) and tumor markers was analyzed using multiple correspondence analysis.

Results. D5S346 was confirmed as a GC- and CRC-related STR locus. For the first time, we established a discriminant formula on the basis of the six STR loci, which was used to estimate the risk coefficient of suffering from $\mathrm{GC}$ and $\mathrm{CRC}$. The model was statistically significant (Wilks' lambda $=0.471, \chi^{2}=30.488, \mathrm{df}=13$, and $\mathrm{p}=0.004$ ). The results of leave-one-out cross validation showed that the sensitivity of the formula was $73.7 \%$ and the specificity was $76.7 \%$. The area under the ROC curve (AUC) was 0.926 , with a sensitivity of $73.7 \%$ and a specificity of 93.3\%. The STR status was shown to have a certain relationship with the expression of some IHC markers and the level of some tumor markers.

Conclusions. The results of this study complement clinical diagnostic criteria and present markers for early prediction of GC and CRC. This approach will aid in improving risk awareness of susceptible individuals and contribute to reducing the incidence of GC and CRC by prevention and early detection.

\section{Introduction}

Gastrointestinal cancer is a leading cause of cancer-related death worldwide (Zhou et al., 2017). Of all types of gastrointestinal cancer, colorectal cancer (CRC) is the most common; CRC is the third most commonly diagnosed cancer in the United States and the fourth in China (Du et al., 2017; Siegel et al., 2017). Among CRC patients, 39\% are diagnosed at the localized stage, for which the 5-year survival rate is $90 \%$. The survival rate declines to $71 \%$ and $14 \%$ for patients diagnosed with regional and distant metastasis, respectively (Siegel et al., 2017). Although the incidence of gastric cancer (GC) is not as high as that of CRC in the United States, GC is the second most common malignancy in China (Zheng et al., 2019). Moreover, GC is the second most common cause of cancer-related death worldwide (Torre et al., 2015). Metastasis greatly affects the efficacy of treatment and is the main cause of fatality from the disease (Gupta \& Massagué, 2006). Therefore, a deeper understanding of the molecular mechanisms in GC and $\mathrm{CRC}$ progression and the identification of early diagnostic biomarkers and predictive signals for the diseases have become urgent issues. 
78

79

80

81

82

83

84

85

86

87

88

89

90

91

92

93

94

95

96

97

98

99

100

101

102

103

104

105

106

107

108

109

110

111

112

113

114

115

116

117

Short tandem repeats (STRs), also known as microsatellites, are small (1-6 base pairs) repeating DNA fragments occurring throughout the entire genome and account for approximately $3 \%$ of the human genome (Nojadeh, Behrouz \& Sakhinia, 2018). These repeats are prone to accumulate mutations during DNA replication owing to a defect in the DNA mismatch repair (MMR) system (Zeinalian et al., 2018). Accumulating mutations in target genes including oncogenes, tumor suppressor genes, or cell cycle-regulating genes with microsatellite repeats lead to frameshift mutations, which can cause protein truncation and tumor progression (Mokarram et al., 2014). Several studies tested for somatic alterations in STR loci and determined that some of these mutations are associated with the diagnosis and prognosis of diseases including prostate (Moya et al., 2018), hepatocellular (Rao, Asch \& Yamada, 2017), gastric (Marrelli et al., 2016), colorectal (Yang et al., 2018), breast (McIver et al., 2014), and lung (Sozzi et al., 1999) carcinomas. Most of these studies (McIver et al., 2014; Marrelli et al., 2016; Rao, Asch \& Yamada, 2017; Moya et al., 2018; Yang et al., 2018) investigated microsatellite alterations, including microsatellite instability (MSI), and loss of heterozygosity (LOH) by analyzing the genotype in tumor tissues, with paired adjacent normal tissues as controls. It was also discovered that circulating cell-free tumor DNA (ctDNA) can be found in various cancers (Bhangu et al., 2017). Therefore, a small number of these studies (Sozzi et al., 1999) used ctDNA instead of tumor tissue DNA to analyze microsatellite alterations by comparison with normal lymph nodes. However, all these studies focused on the auto-microsatellite alterations in the patients themselves. To the best of our knowledge, there have been no reported studies involving comparison of STR loci between patients with cancer of the digestive tract and healthy controls to determine the risk coefficient of suffering from the diseases.

In previous studies, STR loci AR, BAT-25, D5S346, ER1, ER2, and FGA were reported to be closely related to the occurrence of malignant carcinomas. Androgen receptor (AR) is a nuclear transcription factor derived from the X-chromosome (Ryan et al., 2017). The AR gene contains a highly polymorphic repeat motif (CAG) in exon 1 encoding a glutamine tract that is inversely correlated with the transcriptional competence of the receptor (Ackerman et al., 2012). A previous study demonstrated that the CAG repeat sequence is closely related to the development of $\mathrm{CRC}$ and the long $\mathrm{CAG}$ repeat sequence is associated with a low 5-year overall survival (OS) rate in CRC patients (Huang et al., 2015). BAT-25, in introns of the c-kit oncogene, has been extensively studied for its major role in MSI (Zhou et al., 1997). Studies have revealed that MSI was detected in GC (Polom et al., 2017), CRC (Esemuede et al., 2010), and endometrial cancer (Kanopiene et al., 2015). D5S346 appears in introns of the tumor suppressor gene APC, which plays an important role in $\mathrm{Wnt} / \beta$-catenin pathway regulation, cell migration, adhesion, chromosome segregation, and spindle assembly (Zauber, Marotta \& Sabbath-Solitare, 2016). Another study demonstrated that LOH of the D5S346 locus occurred in more than $60 \%$ of esophageal carcinomas and almost all sporadic CRCs as well as many pancreatic and gastric carcinomas (Nair, Naidoo \& Chetty, 2006). Estrogen receptors (ER) $\alpha$ and $\beta$ (coded by the genes

PeerJ reviewing PDF | (2019:01:34098:2:0:NEW 19 Apr 2019) 
$118 E S R 1$ and ESR2, respectively), which are ligand-activated transcription factors, appear to play a

119

120

121

122

123

124

125

126

127

128

129

130

131

132

133

134

135

136

137

138

139

140

141

142

143

144

145

146

147

148

149

150

151

152

153

154

155

156

predominant role in regulating cell proliferation and now serve as the basis for many therapeutic interventions (Narita et al., 2010). Narita et al. (2010) found that longer TA repeats in ESRl were correlated with increased disease-free survival in breast cancer patients. Rudolph et al. (2004) found that longer CA repeats in ESR 2 were potentially associated with an increase in CRC risk. FGA is a compound tetranucleotide repeat found in the third intron of the human alpha fibrinogen locus on the long arm of chromosome 4 (Gettings et al., 2015). A high incidence of alterations in FGA was observed in patients with GC (Vauhkonen et al., 2004) and oral cancer (Pai et al., 2002).

Therefore, in the present study, these six STR loci were analyzed using peripheral blood samples from six colon cancer patients, five rectal cancer patients, eight GC patients, and 30 healthy subjects with an automated fluorochrome-based DNA sequencer. At the same time, using the Fisher linear discriminant analysis (FDA) method, a new discriminant function used to estimate the risk coefficient of suffering from GC and CRC based on the allelic variations at polymorphic STR markers was established. Overall, this study provides further insight into the incidence and patterns of cancer of the digestive tract and will complement clinical diagnostic criteria for patients with these cancers. Whereas previous studies commonly focused on MSI or LOH in tumor tissues, herein, we concentrated on genomic STR types, which are congenital rather than acquired, in the peripheral blood of GC and CRC patients and healthy individuals, allowing for the use of these STR loci in the prediction of inherited genomic susceptibility to GC and CRC in individuals.

\section{Materials \& Methods}

\section{Samples}

A total of 19 samples from six colon cancer patients, five rectal cancer patients, and eight gastric cancer patients (as evidenced by pathological findings), recruited from The Second Hospital of Jilin University (Changchun, China) between December 2016 and December 2017, were included in the study (Table 1). In addition, 30 healthy subjects were recruited from the same city as the control groups. All participants were Han Chinese from northeast China.

\section{Ethics statement and informed statement}

The Ethics Committee of the Second Hospital of Jilin University has a detailed understanding of and approved all experimental protocols in this study (approval number: 2016-39). This study conforms to the provisions of the Declaration of Helsinki (as revised in Fortaleza, Brazil, October 2013). All involved methods were carried out in accordance with relevant guidelines and regulations of the Ethics Committee of the Second Hospital of Jilin University. We informed all participants according to the informed consent for the use of their specimens, and written informed consents were obtained from each participant.

\section{DNA extraction and PCR amplification}


157 Genomic DNA from 49 samples was extracted from $2 \mathrm{ml}$ of peripheral blood using a Genomic

158

159

160

161

162

163

164

165

166

167

168

169

170

171

172

173

174

175

176

177

178

179

180

181

182

183

184

185

186

187

188

189

190

191

192

193

194

195

196

197

DNA Kit (TIANGEN Biotech, Inc., Shanghai, China) according to the manufacturer's instructions. The extracted DNA was quantified using the NanoDrop 2000 spectrophotometer (Thermo Fisher Scientific, Waltham, MA, USA). Six STR markers (AR, Bat-25, D5S346, ER1, ER2, and FGA) were amplified in the Mastercycler ${ }^{\circledR}$ nexus (Eppendorf, Hamburg, Germany) according to the manufacturer's instructions. The details of each STR marker are listed in Table 2. Each PCR reaction mixture contained $0.8 \mu \mathrm{l}$ primer (the concentration of all primers was 10 $\mu \mathrm{M}), 30-300$ ng template DNA, $10 \mu \mathrm{PCR}$ amplification reaction solution, and deionized water to a total volume of $20 \mu \mathrm{l}$. All primer sequences for amplification are listed in Table 3. The PCR reaction conditions were as follows: $95^{\circ} \mathrm{C}$ for $3 \mathrm{~min}$, followed by 10 cycles at $95^{\circ} \mathrm{C}$ for $30 \mathrm{~s}$, $60{ }^{\circ} \mathrm{C}$ for $30 \mathrm{~s}$, and $72{ }^{\circ} \mathrm{C}$ for $30 \mathrm{~s} ; 20$ cycles of $95^{\circ} \mathrm{C}$ for $30 \mathrm{~s}, 55^{\circ} \mathrm{C}$ for $30 \mathrm{~s}$, and $72{ }^{\circ} \mathrm{C}$ for $30 \mathrm{~s}$; and a final extension step at $72{ }^{\circ} \mathrm{C}$ for $6 \mathrm{~min}$.

\section{Fragment size determination}

For determination of the size of each PCR product, the forward primer of each tested STR marker was labeled with a different fluorochrome: $5^{\prime}$ hexachlorofluorescein (HEX) for AR; $5^{\prime}$ carboxyfluorescein (FAM) for Bat-25, D5S346, and ER2; and 5' carboxy-X-rhodamine (ROX) for ER1 and FGA (Table 3). Amplification products $(1 \mu \mathrm{l})$ were mixed with $9.9 \mu \mathrm{l}$ of formamide and $0.1 \mu \mathrm{l}$ of an internal size standard (GenScan ${ }^{\mathrm{TM}} 500 \mathrm{LIZ}{ }^{\circledR}$ Size Standard; Applied Biosystems, Inc., Carlsbad, CA, USA). The mixture was denatured at $95{ }^{\circ} \mathrm{C}$ for $5 \mathrm{~min}$ and chilled for $5 \mathrm{~min}$ in an ice-water bath before capillary electrophoresis with a 3730XL Genetic Analyzer (Applied Biosystems, Inc.). The final size of the obtained PCR products was determined using the Gene Mapper ID software v3.2 (AB SCIEX, Framingham, MA, USA). STR typing determination

Based on the PCR product fragment sizes, the copy number of the STR loci was calculated with the following formula: $\mathrm{X}=$ round $[(\mathrm{S}-\mathrm{N}) / \mathrm{n}]$. In this formula, $\mathrm{X}$ represents the copy number of the STR locus; S represents the fragment size of the PCR product; N represents the base number of the flanking region; $\mathrm{n}$ represents the base number of the repeat motifs; and round represents the omission of decimal fractions smaller than 0.5 and inclusion of all others, including 0.5 , as 1 (Table 4, Fig. 1).

\section{Immunohistochemical (IHC) staining and assessment}

All samples were fixed in 4\% neutral formaldehyde solution and embedded in paraffin. Each tissue block was sectioned at $2-\mu \mathrm{m}$ thickness, dewaxed, hydrated, and antigen-repaired by PT Link (Dako, Agilent Technologies, Santa Clara, CA, USA). Specifically, the sections were placed in the repair solution preheated to $65^{\circ} \mathrm{C}$, incubated for $30 \mathrm{~min}$ at $90^{\circ} \mathrm{C}$, and then cooled to $70^{\circ} \mathrm{C}$. Subsequently, the sections were washed with phosphate-buffered saline (PBS). Primary and secondary antibodies and 3,3' -diaminobenzidine (DAB) solution were applied with the Autostainer Link 48 (Dako, Agilent Technologies). In brief, the sections were incubated with hydrogen peroxide for $10 \mathrm{~min}$, primary antibody for $30 \mathrm{~min}$, and secondary antibody for $20 \mathrm{~min}$ at room temperature. Finally, the sections were counterstained with hematoxylin, routinely dehydrated, cleared, and sealed. 
198

199

200

201

202

203

204

205

206

207

208

209

210

211

212

213

214

215

216

217

218

219

220

221

222

223

224

225

226

227

228

229

230

231

232

233

234

235

236

237

All cases were divided into two groups. EGFR and CDX2 protein expression was determined based on the detection of staining at a particular location: - (no staining) and + (staining). Ki67 and P53 protein expression was determined based on the percentage of immunoreactive cells, which was defined as low expression $(<50 \%)$ and high expression $(\geq 50 \%)$.

\section{Tumor marker detection}

Serum tumor markers were measured by chemiluminescence immunoassay using Quantitative Assay Kits (Tegen, Shanghai, China). The normal cuto $\square$ values for these markers were as follows: CA199 $<35 \mathrm{U} / \mathrm{ml}, \mathrm{CEA}<5 \mathrm{ng} / \mathrm{ml}, \mathrm{CA} 125<35 \mathrm{U} / \mathrm{ml}, \mathrm{CA} 242<20 \mathrm{U} / \mathrm{ml}$, and CA72-4 $<6.9 \mathrm{U} / \mathrm{ml}$.

\section{Statistical analysis}

Statistical analysis was performed using the SPSS Statistics 22.0 software (SPSS Inc., Chicago, IL, USA). Normally distributed variables were compared by Student's t-test and presented as means \pm standard deviation. According to the STR locus typing, FDA was performed to establish the linear combination to distinguish the GC group from the healthy group. FDA served as a dimension reduction tool to identify a linear function of the variables to maximize differences between samples of multiple classes and to minimize differences between samples of the same class (Zou et al., 2018). Leave-one-out cross validation, in which each case was classified according to the formula derived from all cases other than that case, was used to validate the accuracy of the FDA. Receiver operating characteristic (ROC) curves were also used to validate the accuracy of the FDA; an area under the ROC curve (AUC) between 0.5 and 0.7 represented low diagnostic value, between 0.7 and 0.9 represented medium diagnostic value, and more than 0.9 represented high diagnostic value. The results were considered statistically significant at $\mathrm{p}<0.05$. The correspondence between the STR locus typing and IHC and tumor markers was analyzed using multiple correspondence analysis, which is a multivariate statistical technique used to explore the simultaneous relationships between variables (Leandro-Merhi \& Aquino, 2017).

\section{Results}

\section{Fragment size determination}

The fragment size of each STR locus in all samples was detected (DatasetS1). An example electropherogram is shown in Fig. 2.

\section{STR typing determination}

We used the copy number of each STR locus to represent the STR typing. The calculation of the copy number is detailed in Table 4, the results of which are shown in Fig. 3 and DatasetS2.

Because each STR locus contains two alleles, whose copy numbers may be different, we divided each STR locus into two indexes: short repeat motif (marked as "-S") and long repeat motif (marked as "-L"). By comparing the copy number of each STR locus between GC and CRC patients and healthy subjects, we found that the copy number of AR-L was lower in GC and CRC patients than in healthy subjects ( $26.16 \pm 2.91$ vs. $27.80 \pm 2.17, \mathrm{p}=0.032)$; the copy number of D5S346-S was higher in GC and CRC patients than in healthy subjects (14.84 \pm 2.66 vs. 
$23813.23 \pm 1.45, \mathrm{p}=0.027)$; the copy number of D5S346-L was higher in $\mathrm{GC}$ and CRC patients than 239 in healthy subjects $(18.79 \pm 4.21$ vs. $15.50 \pm 3.95, \mathrm{p}=0.009)$; and the copy number of ER2-L was 240 lower in GC and CRC patients than in healthy subjects (19.74 2.77 vs. $21.30 \pm 2.19, \mathrm{p}=0.037)$.

241 There was no significant difference in the copy number of other STR loci between the GC and 242 CRC patients and healthy subjects ( $\mathrm{p}>0.05)$.

\section{Establishment of discriminant function}

244 To distinguish the GC and CRC group from the healthy group based on the copy number of STR 245 loci, an FDA of the 12 alleles of the six STR loci was performed. According to the results of 246 statistical analysis, we obtained the following discriminant functions (Wilks' lambda $=0.471$, $247 \quad \chi^{2}=30.488, \mathrm{df}=13$, and $\left.\mathrm{p}=0.004\right)$ :

248

249

250

251

252

253

254

255

256

257

258

259

260

261

262

263

264

265

266

267

268

269

270

271

272

273

274

275

276

277

$\mathrm{Cfunc}_{1}=12.431 \mathrm{X} 1-3.900 \mathrm{X} 2+16.475 \mathrm{X} 3+117.320 \mathrm{X} 4-2.841 \mathrm{X} 5-0.399 \mathrm{X} 6+0.971 \mathrm{X} 7+7.972$ X8+0.185 X9-3.214 X10+6.034 X11-3.737 X12-28.835 X13-1776.227 (GC patient);

$\mathrm{Cfunc}_{2}=12.290 \mathrm{X} 1-3.378 \mathrm{X} 2+16.342 \mathrm{X} 3+118.680 \mathrm{X} 4-3.252 \mathrm{X} 5-0.757 \mathrm{X} 6+1.308 \mathrm{X} 7+7.836$ X8+0.163 X9-2.917 X10+5.877 X11-4.148 X12-30.834 X13-1803.632 (healthy control).

In the discriminant formulas, X1-X12 represent the copy number of different STR loci (Table 5). If the subject is female, $\mathrm{X} 13$ was zero; if the subject is male, $\mathrm{X} 13$ was one. The values of $\mathrm{Cfunc}_{1}$ and $\mathrm{Cfunc}_{2}$ were calculated by substituting the copy number of STR loci into the discriminant function. By comparing the $\mathrm{Cfunc}_{1}$ and $\mathrm{Cfunc}_{2}$ values, subjects with unknown classification were classified according to the following principles: if $\mathrm{Cfunc}_{1}>\mathrm{Cfunc}_{2}$, the subjects were classified into the GC and CRC group; if $\mathrm{Cfunc}_{1}<\mathrm{Cfunc}_{2}$, the subjects were classified into the healthy group.

\section{Accuracy and diagnostic value of the discriminant formula}

Leave-one-out cross validation was performed to validate the accuracy of the discriminant formula. The results showed that in the GC and CRC group, 14 patients (73.7\%) were correctly classified, with a misclassification rate of $26.3 \%$; in the healthy group, 23 cases $(76.7 \%)$ were correctly classified, with a misclassification rate of $23.3 \%$ (Table 6 ).

An important measure to validate the accuracy of a prediction formula is the ROC curve. In the present study, ROC curves were generated based on the value of Cfunc ( $\left.\mathrm{Cfunc}_{1}-\mathrm{Cfunc}_{2}\right)$ calculated for each case (range from -5.896 to 5.434) and the copy number of all the STR loci. The results showed that the area under the ROC curve (AUC) of Cfunc was $0.926(95 \% \mathrm{CI}$ 0.851-1.000), which indicated a high diagnostic value (Fig. 4). Considering 0 as the criterion for differential diagnosis, the sensitivity of the ROC curve was 0.737 , and the specificity was 0.933 . Among the STR loci, the AUC of D5S346-S was 0.894, and the AUC of D5S346-L was 0.798, which indicated a medium diagnostic value. Contrarily, the AUC of other STR loci was between 0.305 and 0.622 , which indicated no or low diagnostic value (Fig. S1, Table 7).

PeerJ reviewing PDF | (2019:01:34098:2:0:NEW 19 Apr 2019) 


\section{Correspondence between STR typing and IHC markers}

279 In order to explore the correlation between the STR locus status and commonly used IHC 280 markers, including EGFR, CDX2, Ki67, and P53, Student's t-test and multiple correspondence 281 analysis were performed. The results of Student's t-test showed that there was no significant 282 difference in the copy number of STR loci between the IHC (+)/high expression group and IHC $283(-) /$ low expression group $(p>0.05)$ (Fig. S2). The results of multiple correspondence analysis 284 showed that the copy number of AR was related to the expression of CDX2; the copy number of 285 Bat-25 was related to the expression of Ki67; and the copy numbers of ER2 and FGA were 286 related to the expression of P53 (Fig. 5a).

287 Correspondence between STR typing and tumor markers

288 Student's t-test and multiple correspondence analysis were performed to explore the correlation

289

290

291

292

293

294

295

296

297

298

299

300

301

302

303

304

305

306

307

308

309

310

311

312

313

314

315

316

317 between the STR locus status and commonly used tumor markers, including CA125, CA19-9, CA242, CA72-4, and CEA. The results of Student's t-test showed that there was no significant difference in the copy number of STR loci between the normal and abnormal tumor marker groups ( $p>0.05$ ) (Fig. S3). The results of multiple correspondence analysis showed that the copy number of AR was related to the level of CA242; the copy number of Bat-25 was related to the level of CA19-9; the copy number of ER1 was related to the level of CA125; and the copy number of FGA was related to the level of CEA (Fig. 5b).

\section{Discussion}

It is widely accepted that cancer is influenced by many genes that interact as well as the environment (Qi et al., 2018). Therefore, single genetic alterations do not provide sufficient information about a given disease. In the present study, we established a new method that can be used for early diagnosis and prediction of genomic susceptibility to GC and CRC in a Han population in northern China by integrated analysis of multiple STR loci using FDA.

Initially, on the basis of several previous studies, we focused on six different STR loci, including AR, BAT-25, D5S346, ER1, ER2, and FGA, which were reported to be closely related to the occurrence of malignant carcinomas. We divided each STR locus into two allelotypes, short repeat motif and long repeat motif. This method avoids influence from two alleles at one STR locus with different numbers of copies; each allele has the same average copy number compared with that of another individual. By comparing the copy number of a single STR locus between GC and CRC patients and healthy subjects, we found that the copy number of both D5S346-S and D5S346-L was higher in GC and CRC patients than in healthy subjects $(\mathrm{p}<0.05$ and $\mathrm{p}<$ 0.01 , respectively). This result indicated that D5S346 is a GC- and CRC-related STR locus, which is similar to results of previous studies (Stemmermann et al., 1994; Nair, Naidoo \& Chetty, 2006). Then, we compiled these 12 alleles to conduct an integrated analysis using the FDA method. FDA is a classical approach to identify a linear function of variables to distinguish samples from different groups as much as possible (Zou et al., 2018). This method has been widely applied in many fields, including facial recognition (Ruiz-Del-Solar \& Navarrete, 2005), 
318 market research (Imp et al., 2018), and disease classification (Zou et al., 2018). In the present 319 study, we successfully established a discriminant formula to distinguish patients with GC and 320 CRC from healthy controls using the FDA method $(\mathrm{p}<0.01)$. The result of the leave-one-out

321

322

323

324

325

326

327

328

329

330

331

332

333

334

335

336

337

338

339

340

341

342

343

344

345

346

347

348

349

350

351

352

353

354

355

356

357 cross validation revealed that the sensitivity of the discriminant formula was 0.737 and the specificity was 0.767 . We also used another method, ROC curve analysis, to validate the accuracy of the discriminant formula based on the value of Cfunc, which was calculated by substituting the copy number of each STR locus into the function. The results showed that the AUC of Cfunc was 0.926, which was higher than the AUC of D5S346 (0.894 and 0.798) and other STR loci $(0.300-0.610)$. This result indicated that the diagnostic and predictive value of the discriminant formula was higher than that of the single D5S346 locus, while other STR loci had no significant diagnostic and predictive value. In addition to gastrointestinal cancer, we have conducted similar studies in other cancers, such as lung cancer and breast cancer. Some results of the previous studies are similar to the current findings. However, the potentially valuable STR loci identified in the other cancers did not completely coincide with the six loci identified in the current study.

Although STR alterations have been widely studied in GC and CRC, no studies to our knowledge have compared these polymorphic genotypes with IHC and tumor markers. In this context, we intended to study the relationships between them using Student's t-test and multiple correspondence analysis. Four IHC markers (EGFR, CDX2, Ki67, and P53) were selected for this study, all of which were previously reported to be associated with the occurrence, diagnosis, or prognosis of GC or CRC. Epidermal growth factor receptor (EGFR) is a transmembrane glycoprotein that represents one of the four members of the ErbB family of tyrosine kinase receptors (Singh et al., 2016). Overexpression of EGFR is frequently associated with metastasis and therapy of CRC (Yazdi et al., 2015). Caudal-related homeobox transcription factor (CDX2) is an intestinal transcription factor whose loss is associated with high tumor grade, advanced stage in CRC (Reggiani et al., 2017), and poor prognosis in GC (Wang et al., 2012). Ki67 is a nuclear proliferation-associated antigen that is expressed in the growth and synthesis phases of the cell cycle but not in the resting phase. The Ki67 proliferation index increases during the transformation of intestinal metaplasia to gastric carcinoma (Zheng et al., 2010). P53 is encoded by TP53 gene, which is one of the most important tumor suppressor genes and the main cellcycle checkpoint. The high expression of dysfunctional P53 is common in CRC, as it plays a role in the classical adenoma to carcinoma succession (Mármol et al., 2017). In the present study, because of the limited sample size, Ki67 and P53 protein expression was divided into only two groups (low expression and high expression groups) instead of smaller subgroups, unlike the clinical method used to score these markers. The results of Student's t-test indicated that there was no relationship between STR loci and IHC or tumor markers. However, the results of multiple correspondence analysis indicated that the copy number of AR was related to the expression of CDX2 and the level of CA242; the copy number of Bat-25 was related to the expression of Ki67 and the level of CA19-9; the copy number of ER1 was related to the level of

PeerJ reviewing PDF | (2019:01:34098:2:0:NEW 19 Apr 2019) 
358

359

360

361

362

363

364

365

366

367

368

369

370

371

372

373

374

375

376

377

378

379

380

381

382

383

384

385

386

387

388

389

390

391

392

393

394

395

396

397

CA125; the copy numbers of ER2 and FGA were related to the expression of P53; and the copy number of FGA was related to the expression of P53 and the level of CEA. The specific mechanism and clinical significance of the relationship between STR loci and IHC or tumor markers require further experiments for confirmation.

There are some limitations in the present study. Because of the insufficient sample size, we did not perform correlation analysis between STR variation and patient clinical and pathological characteristics. We believe that more valuable results, which may provide new insight into prognostic evaluation and treatment determination, will be obtained with a larger sample size.

\section{Conclusions}

In conclusion, we confirmed that D5S346 is a GC- and CRC-related STR locus. For the first time, we established a discriminant formula, which was used to estimate the risk coefficient of GC and CRC in a Han population residing in northern China as well as predict inherited genomic susceptibility to the diseases by analyzing the STR typing of genomic DNA. These findings provide supporting evidence for use of STR markers as diagnostic and susceptibility biomarkers for GC and CRC patients. Additionally, we revealed that a relationship between the STR locus and IHC or tumor markers may exist. Nonetheless, the specific mechanism and clinical significance of the relationship require further experiments for confirmation.

\section{References}

Ackerman CM, Lowe LP, Lee H, Hayes MG, Dyer AR, Metzger BE, Lowe WL, Urbanek M. 2012. Ethnic variation in allele distribution of the androgen receptor (AR) (CAG)n repeat. Journal of andrology 33:210-215 DOI 10.2164/jandrol.111.013391.

Bhangu JS, Taghizadeh H, Braunschmid T, Bachleitner-Hofmann T, Mannhalter C. 2017. Circulating cell-free DNA in plasma of colorectal cancer patients - A potential biomarker for tumor burden. Surgical oncology 26:395-401 DOI 10.1016/j.suronc.2017.08.001.

Du LB, Li HZ, Wang YQ, Zhu C, Zheng RS, Zhang SW, Chen WQ, He J. 2017. [Report of colorectal cancer incidence and mortality in China, 2013]. Zhonghua zhong liu za zhi [Chinese journal of oncology] 39:701-706 DOI 10.3760/cma.j.issn.02533766.2017.09.012.

Esemuede I, Forslund A, Khan SA, Qin LX, Gimbel MI, Nash GM, Zeng Z, Rosenberg S, Shia J, Barany F, Paty PB. 2010. Improved testing for microsatellite instability in colorectal cancer using a simplified 3-marker assay. Annals of surgical oncology 17:3370-3378 DOI 10.1245/s10434-010-1147-4.

Gettings KB, Aponte RA, Vallone PM, Butler JM. 2015. STR allele sequence variation: Current knowledge and future issues. Forensic science international. Genetics 18:118-130 DOI 10.1016/j.fsigen.2015.06.005.

Gupta GP, Massagué J. 2006. Cancer metastasis: building a framework. Cell 127:679-695 DOI 10.1016/j.cell.2006.11.001. 
398

399

400

401

402

403

404

405

406

407

408

409

410

411

412

413

414

415

416

417

418

419

420

421

422

423

424

425

426

427

428

429

430

431

432

433

434

435

Huang R, Wang G, Song Y, Wang F, Zhu B, Tang Q, Liu Z, Chen Y, Zhang Q, Muhammad S, Wang X. 2015. Polymorphic CAG Repeat and Protein Expression of Androgen Receptor Gene in Colorectal Cancer. Molecular cancer therapeutics 14:1066-1074 DOI 10.1158/1535-7163.MCT-14-0620.

IMP H, GMD C, Cosmam LC, DRM A, Busanello M, Sippert MR, Damiani C, APA A, Velho JP. 2018. Multivariate analysis relating milk production, milk composition, and seasons of the year. Anais da Academia Brasileira de Ciências DOI 10.1590/00013765201820180345.

Kanopiene D, Vidugiriene J, Valuckas KP, Smailyte G, Uleckiene S, Bacher J. 2015. Endometrial cancer and microsatellite instability status. Open medicine 10:70-76 DOI 10.1515/med-2015-0005.

Leandro-Merhi VA, JLB A. 2017. RELATIONSHIP BETWEEN NUTRITIONAL STATUS AND THE CLINICAL OUTCOMES OF PATIENTS WITH AND WITHOUT NEOPLASMS ACCORDING TO MULTIPLE CORRESPONDENCE ANALYSIS. Arquivos de gastroenterologia 54:148-155 DOI 10.1590/S0004-2803.201700000-05.

Marrelli D, Polom K, Pascale V, Vindigni C, Piagnerelli R, De Franco L, Ferrara F, Roviello G, Garosi L, Petrioli R, Roviello F. 2016. Strong Prognostic Value of Microsatellite Instability in Intestinal Type Non-cardia Gastric Cancer. Annals of surgical oncology 23:943-950 DOI 10.1245/s10434-015-4931-3.

Mármol I, Sánchez-de-Diego C, Pradilla DA, Cerrada E, Rodriguez YMJ. 2017. Colorectal Carcinoma: A General Overview and Future Perspectives in Colorectal Cancer. International journal of molecular sciences 18: DOI 10.3390/ijms18010197.

McIver LJ, Fonville NC, Karunasena E, Garner HR. 2014. Microsatellite genotyping reveals a signature in breast cancer exomes. Breast cancer research and treatment 145:791-798 DOI 10.1007/s10549-014-2908-8.

Mokarram P, Rismanchi M, Alizadeh NM, Mirab SS, Paryan M, Alipour A, Honardar Z, Kavousipour S, Naghibalhossaini F, Mostafavi-Pour Z, Monabati A, Hosseni SV, Shamsdin SA. 2014. Microsatellite instability typing in serum and tissue of patients with colorectal cancer: comparing real time PCR with hybridization probe and highperformance liquid chromatography. Molecular biology reports 41:2835-2844 DOI 10.1007/s11033-014-3138-1.

Moya L, Lai J, Hoffman A, Srinivasan S, Panchadsaram J, Chambers S, Clements JA, Batra J. 2018. Association Analysis of a Microsatellite Repeat in the TRIB1 Gene With Prostate Cancer Risk, Aggressiveness and Survival. Frontiers in genetics 9:428 DOI 10.3389/fgene.2018.00428.

Nair KS, Naidoo R, Chetty R. 2006. Microsatellite analysis of the APC gene and immunoexpression of E-cadherin, catenin, and tubulin in esophageal squamous cell carcinoma. Human pathology 37:125-134 DOI 10.1016/j.humpath.2005.10.009.

PeerJ reviewing PDF | (2019:01:34098:2:0:NEW 19 Apr 2019) 
436 Narita D, Anghel A, Cimpean AM, Izvernariu D, Cireap N, Ilina R, Ursoniu S. 2010. Interaction

437

438

439

440

441

442

443

444

445

446

447

448

449

450

451

452

453

454

455

456

457

458

459

460

461

462

463

464

465

466

467

468

469

470

471

472

473

474

475 between estrogens and androgen receptor genes microsatellites, prostate-specific antigen and androgen receptor expressions in breast cancer. Neoplasma 57:198-206.

Nojadeh JN, Behrouz SS, Sakhinia E. 2018. Microsatellite instability in colorectal cancer. EXCLI journal 17:159-168 DOI 10.17179/excli2017-948.

Pai CY, Hsieh LL, Tsai CW, Chiou FS, Yang CH, Hsu BD. 2002. Allelic alterations at the STR markers in the buccal tissue cells of oral cancer patients and the oral epithelial cells of healthy betel quid-chewers: an evaluation of forensic applicability. Forensic science international 129:158-167.

Polom K, Das K, Marrelli D, Roviello G, Pascale V, Voglino C, Rho H, Tan P, Roviello F. 2017. KRAS Mutation in Gastric Cancer and Prognostication Associated with Microsatellite Instability Status. Pathology oncology research : POR DOI 10.1007/s12253-017-0348-6.

Qi X, Yu Y, Ji N, Ren S, Xu Y, Liu H. 2018. Genetic risk analysis for an individual according to the theory of programmed onset, illustrated by lung and liver cancers. Gene 673:107-111 DOI 10.1016/j.gene.2018.06.044.

Rao CV, Asch AS, Yamada HY. 2017. Frequently mutated genes/pathways and genomic instability as prevention targets in liver cancer. Carcinogenesis 38:2-11 DOI 10.1093/carcin/bgw118.

Reggiani BL, Lionti S, Vitarelli E, Barresi V. 2017. Prognostic significance of CDX2 immunoexpression in poorly differentiated clusters of colorectal carcinoma. Virchows Archiv: an international journal of pathology 471:731-741 DOI 10.1007/s00428-0172219-7.

Rudolph A, Shi H, Försti A, Hoffmeister M, Sainz J, Jansen L, Hemminki K, Brenner H, ChangClaude J. 2014. Repeat polymorphisms in ESR2 and AR and colorectal cancer risk and prognosis: results from a German population-based case-control study. BMC cancer 14:817 DOI 10.1186/1471-2407-14-817.

Ruiz-Del-Solar J, Navarrete P. 2005. Eigenspace-based face recognition: A comparative study of different approaches. IEEE TRANSACTIONS ON SYSTEMS MAN AND CYBERNETICS PART C-APPLICATIONS AND REVIEWS 35:315-325 DOI 10.1109/TSMCC.2005.848201.

Ryan CP, Georgiev AV, McDade TW, Gettler LT, DTA E, Rzhetskaya M, Agustin SS, Hayes MG, Kuzawa CW. 2017. Androgen receptor polyglutamine repeat length (AR-CAGn) modulates the effect of testosterone on androgen-associated somatic traits in Filipino young adult men. American journal of physical anthropology 163:317-327 DOI 10.1002/ajpa.23208.

Siegel RL, Miller KD, Fedewa SA, Ahnen DJ, RGS M, Barzi A, Jemal A. 2017. Colorectal cancer statistics, 2017. CA: a cancer journal for clinicians 67:177-193 DOI $10.3322 /$ caac. 21395 .

Singh D, Attri BK, Gill RK, Bariwal J. 2016. Review on EGFR Inhibitors: Critical Updates. Mini reviews in medicinal chemistry 16:1134-1166. 
476 Sozzi G, Musso K, Ratcliffe C, Goldstraw P, Pierotti MA, Pastorino U. 1999. Detection of 477 microsatellite alterations in plasma DNA of non-small cell lung cancer patients: a 478 prospect for early diagnosis. Clinical cancer research : an official journal of the American $479 \quad$ Association for Cancer Research 5:2689-2692.

480 Stemmermann G, Heffelfinger SC, Noffsinger A, Hui YZ, Miller MA, Fenoglio-Preiser CM.

481

482

483

484

485

486

487

488

489

490

491

492

493

494

495

496

497

498

499

500

501

502

503

504

505

506

507

508

509

510

511

512

513 1994. The molecular biology of esophageal and gastric cancer and their precursors: oncogenes, tumor suppressor genes, and growth factors. Human pathology 25:968-981.

Torre LA, Bray F, Siegel RL, Ferlay J, Lortet-Tieulent J, Jemal A. 2015. Global cancer statistics, 2012. CA: a cancer journal for clinicians 65:87-108 DOI 10.3322/caac.21262.

Vauhkonen H, Hedman M, Vauhkonen M, Kataja M, Sipponen P, Sajantila A. 2004. Evaluation of gastrointestinal cancer tissues as a source of genetic information for forensic investigations by using STRs. Forensic science international 139:159-167 DOI 10.1016/j.forsciint.2003.10.016.

Wang XT, Wei WY, Kong FB, Lian C, Luo W, Xiao Q, Xie YB. 2012. Prognostic significance of $\mathrm{Cdx} 2$ immunohistochemical expression in gastric cancer: a meta-analysis of published literatures. Journal of experimental \& clinical cancer research: CR 31:98 DOI 10.1186/1756-9966-31-98.

Yang Y, Wang D, Jin L, Wu G, Bai Z, Wang J, Yao H, Zhang Z. 2018. Prognostic value of the combination of microsatellite instability and BRAF mutation in colorectal cancer. Cancer management and research 10:3911-3929 DOI 10.2147/CMAR.S169649.

Yazdi MH, Faramarzi MA, Nikfar S, Abdollahi M. 2015. A Comprehensive Review of Clinical Trials on EGFR Inhibitors Such as Cetuximab and Panitumumab as Monotherapy and in Combination for Treatment of Metastatic Colorectal Cancer. Avicenna journal of medical biotechnology 7:134-144.

Zauber P, Marotta S, Sabbath-Solitare M. 2016. Copy number of the Adenomatous Polyposis Coli gene is not always neutral in sporadic colorectal cancers with loss of heterozygosity for the gene. BMC cancer 16:213 DOI 10.1186/s12885-016-2243-z.

Zeinalian M, Hashemzadeh-Chaleshtori M, Salehi R, Emami MH. 2018. Clinical Aspects of Microsatellite Instability Testing in Colorectal Cancer. Advanced biomedical research 7:28 DOI 10.4103/abr.abr_185_16.

Zheng RS, Sun KX, Zhang SW, Zeng HM, Zou XN, Chen R, Gu XY, Wei WW, He J. 2019. [Report of cancer epidemiology in China, 2015]. Zhonghua zhong liu za zhi [Chinese journal of oncology] 41:19-28 DOI 10.3760/cma.j.issn.0253-3766.2019.01.005.

Zheng Y, Wang L, Zhang JP, Yang JY, Zhao ZM, Zhang XY. 2010. Expression of p53, c-erbB-2 and Ki67 in intestinal metaplasia and gastric carcinoma. World journal of gastroenterology 16:339-344.

Zhou DD, Liu XF, Lu CW, Pant OP, Liu XD. 2017. Long non-coding RNA PVT1: Emerging biomarker in digestive system cancer. Cell proliferation 50: DOI 10.1111/cpr.12398. 
514 Zhou XP, Hoang JM, Cottu P, Thomas G, Hamelin R. 1997. Allelic profiles of mononucleotide 515 repeat microsatellites in control individuals and in colorectal tumors with and without 516 replication errors. Oncogene 15:1713-1718 DOI 10.1038/sj.onc.1201337.

517 Zou M, Sun C, Liang S, Sun Y, Li D, Li L, Fan L, Wu L, Xia W. 2018. Fisher discriminant

518 analysis for classification of autism spectrum disorders based on folate-related

519 metabolism markers. The Journal of nutritional biochemistry 64:25-31 DOI

520

521

522

523

524

525

526

527

528

529

530 10.1016/j.jnutbio.2018.09.023.

\section{Figure legends}

Figure 1: Diagram of the method of calculation of copy numbers, with the FGA locus as an example.

Figure 2: Example electropherograms of AR (A), Bat-25 (B), D5S346 (C), ER1 (D), ER2 (E), and FGA (F). The numbers above each peak indicate the allele fragment length.

531

532

533

534 Electropherograms containing one peak (A and B) represent homozygosity, whereas electropherograms containing two peaks $(\mathrm{C}-\mathrm{F})$ represent heterozygosity.

535

Figure 3: Copy number of AR (A), Bat-25 (B), D5S346 (C), ER1 (D), ER2 (E), and FGA (F) between GC and CRC patients and healthy controls. "-S" represents the short repeat motif of

536

537 STR alleles; "-L" represents the long repeat motif of STR alleles. GC, gastric cancer; CRC, colorectal cancer. Statistical significance is indicated by asterisks: ${ }^{*}, \mathrm{p}<0.05 ;{ }^{* *}, \mathrm{p}<0.01$.

538

539

Figure 4: ROC curve of Cfunc.

540

541

Figure 5: Results of multiple correspondence analysis. (A) The correlation between the copy

542 numbers of STR loci and IHC markers in GC and CRC. (B) The correlation between the copy

543 numbers of STR loci and tumor markers in GC and CRC. GC, gastric cancer; CRC, colorectal 544 cancer.

545

546

Figure S1: ROC curves of the copy number of all STR loci.

547

548

Figure S2: Copy number of STR loci between the IHC (+)/high expression group and IHC 549 $(-) /$ low expression group. Copy number of STR loci between EGFR (-) and (+) groups (A), CDX2 (-) and (+) groups (B), low and high Ki67 expression groups (C), and low and high P53 551 expression groups (D).

552

553

Figure S3: Copy number of STR loci between the normal and abnormal tumor marker 
554 groups. Copy number of STR loci between normal and abnormal CA199 groups (A), normal and 555 abnormal CEA groups (B), normal and abnormal CA125 groups (C), normal and abnormal

556 CA242 groups (D), and normal and abnormal CA72-4 groups (E). 
Figure 1

Diagram of the method of calculation of copy numbers, with the FGA locus as an example.

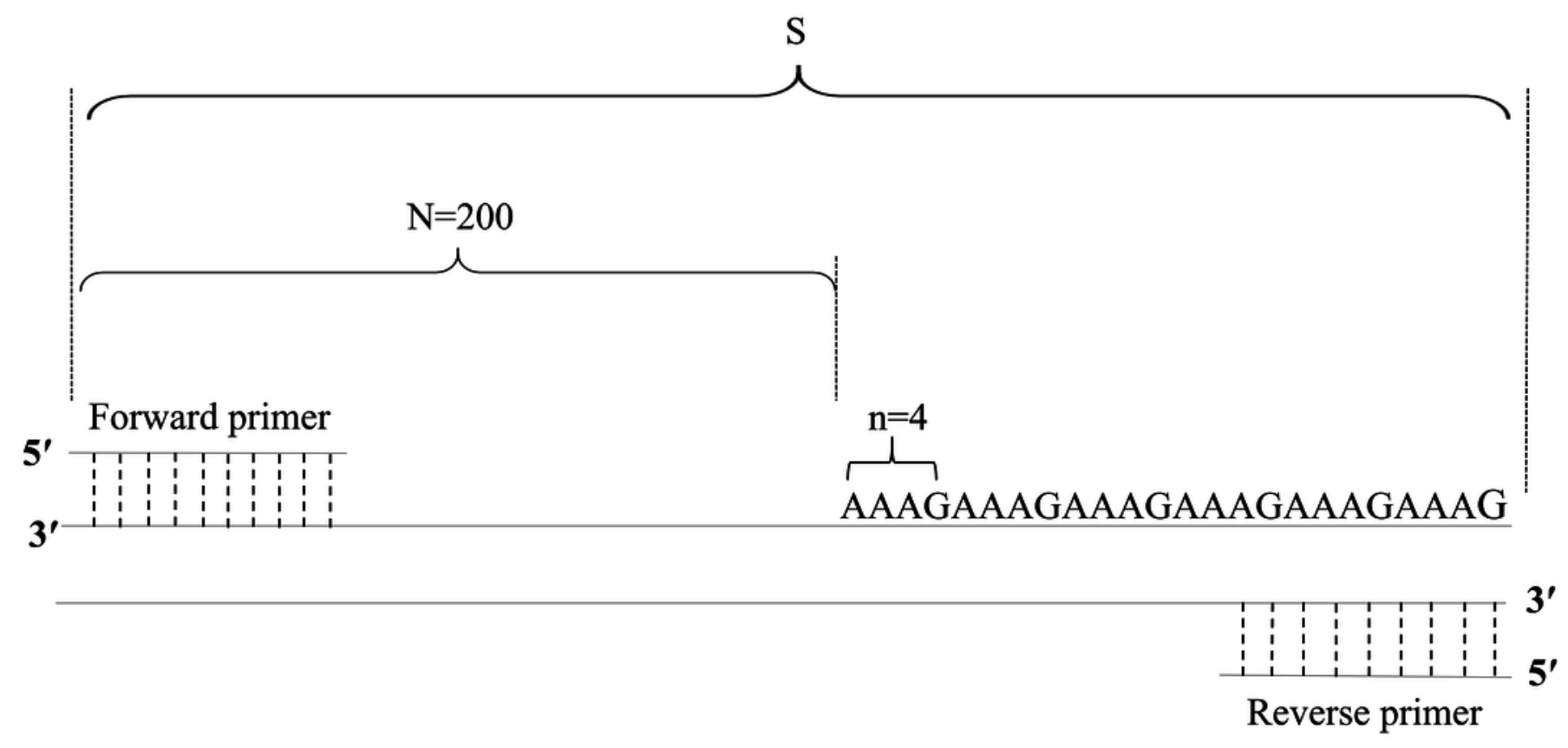


Figure 2

Example electropherograms of AR (A), Bat-25 (B), D5S346 (C), ER1 (D), ER2 (E), and FGA (F).

The numbers above each peak indicate the allele fragment length. Electropherograms containing one peak ( $A$ and $B$ ) represent homozygosity, whereas electropherograms containing two peaks (C-F) represent heterozygosity.

A

266

280

B

399

413

C

224 252

AR

Bat-25

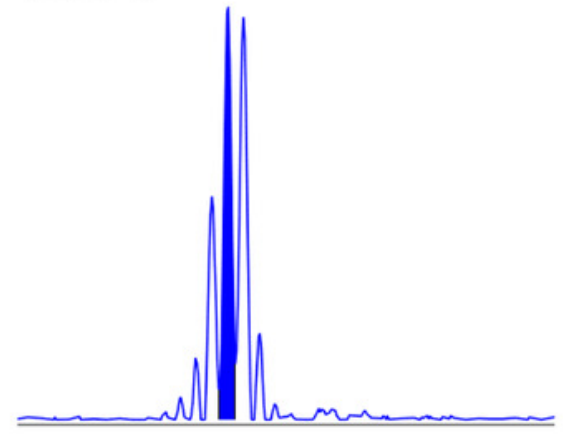

D5S346
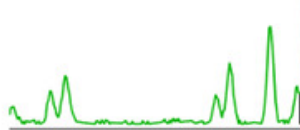

D

392

${ }_{406} \mathrm{E}$

308

322

\section{ER2}

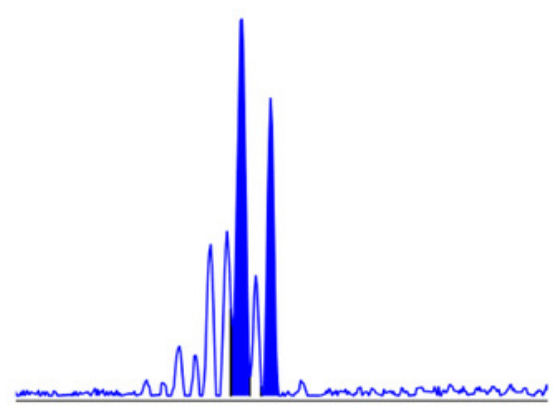

ER1

E

F

245

259
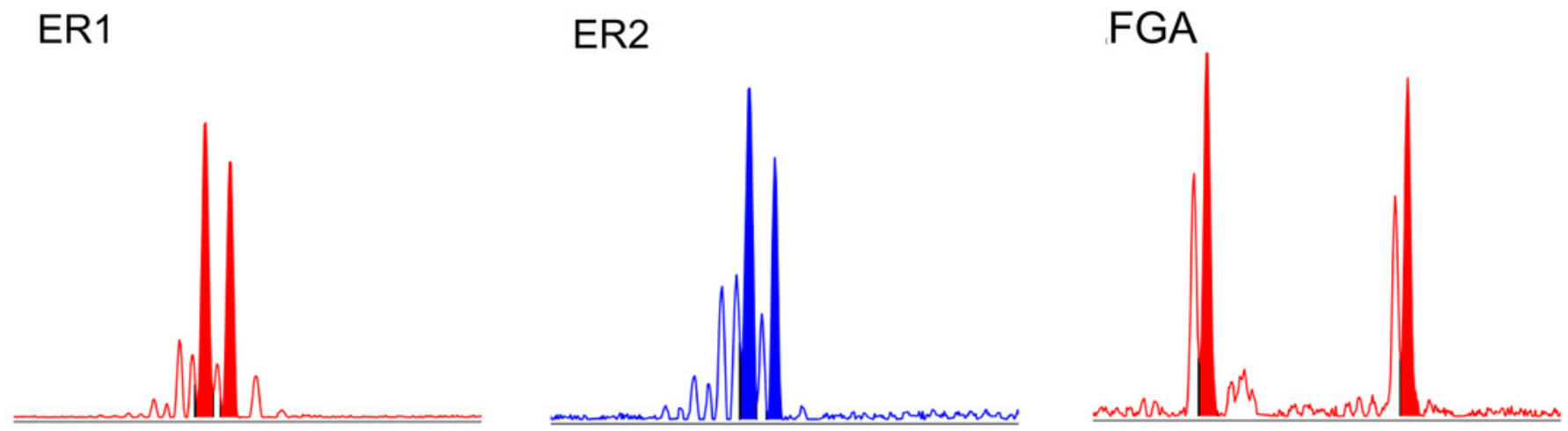
Figure 3

Copy number of AR (A), Bat-25 (B), D5S346 (C), ER1 (D), ER2 (E), and FGA (F) between $\mathrm{GC}$ and $\mathrm{CRC}$ patients and healthy controls.

"-S" represents the short repeat motif of STR alleles; "-L" represents the long repeat motif of STR alleles. GC, gastric cancer; CRC, colorectal cancer. Statistical significance is indicated by asterisks: *, $\mathrm{p}<0.05 ; * *, \mathrm{p}<0.01$.

*Note: Auto Gamma Correction was used for the image. This only affects the reviewing manuscript. See original source image if needed for review. 
A

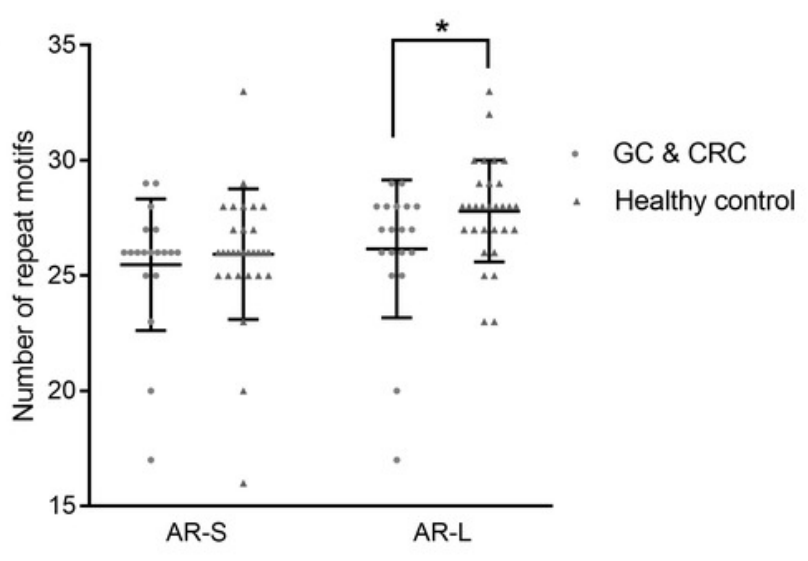

C

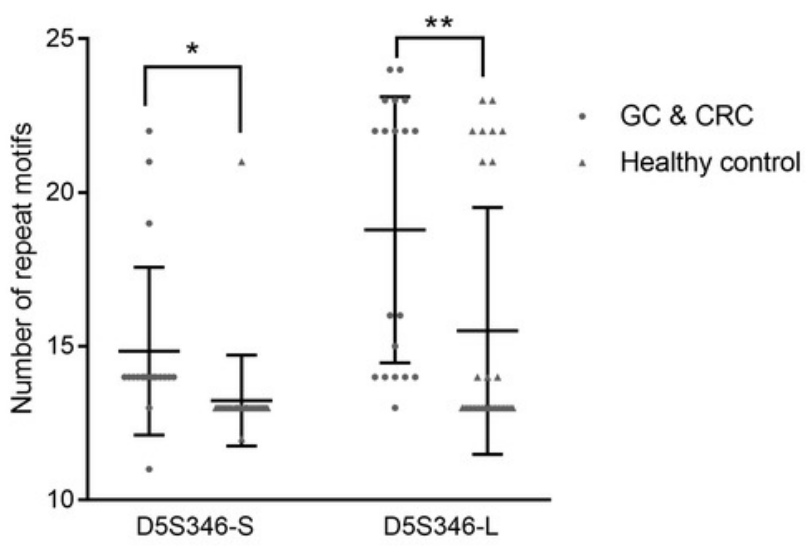

E

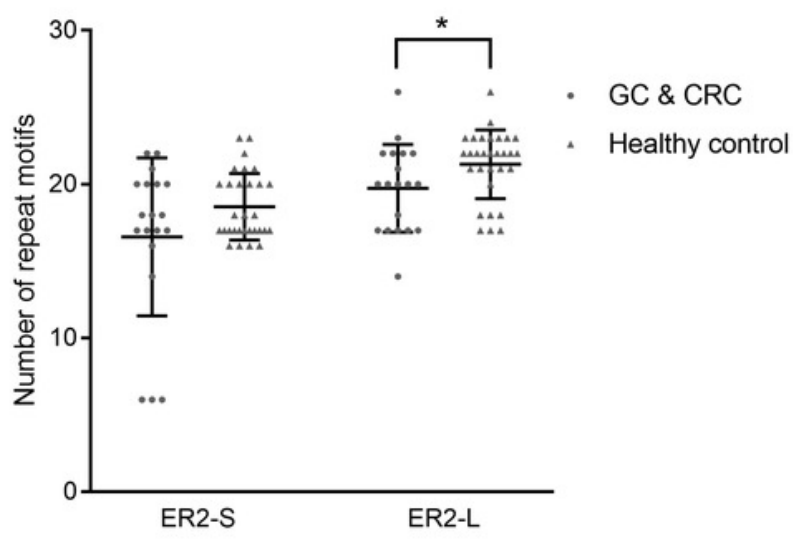

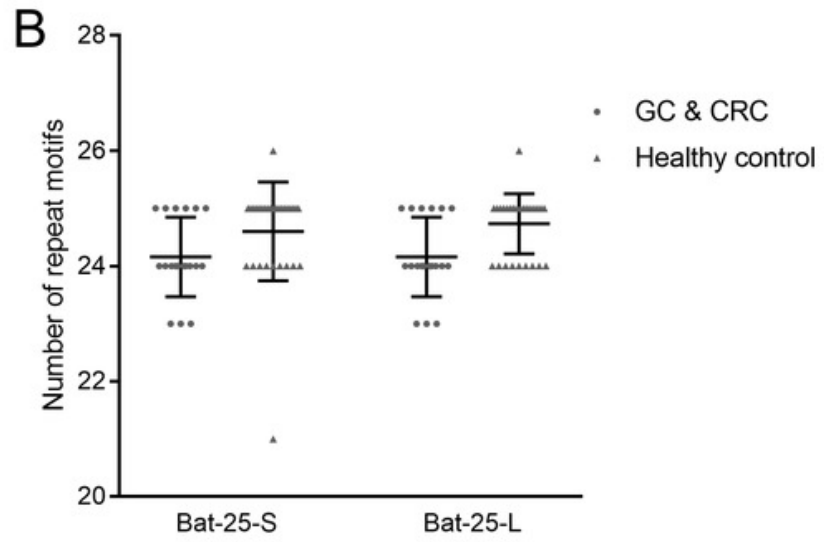
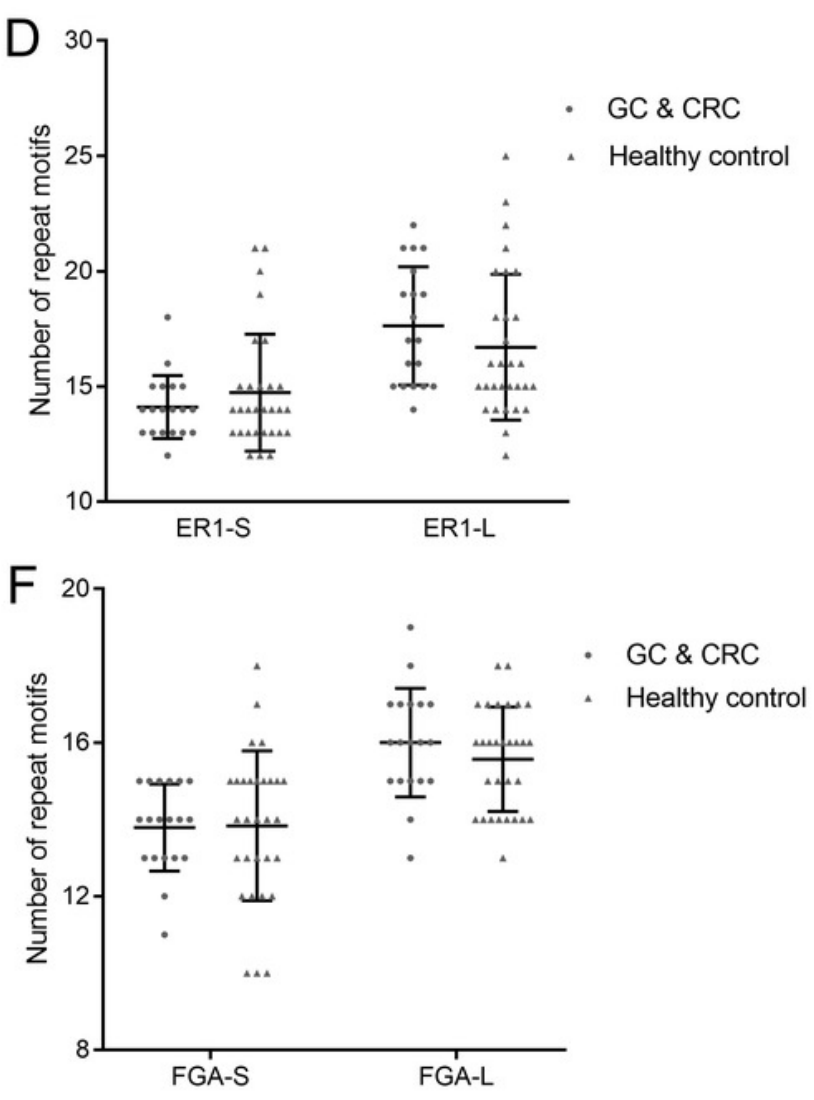
Figure 4

ROC curve of Cfunc.

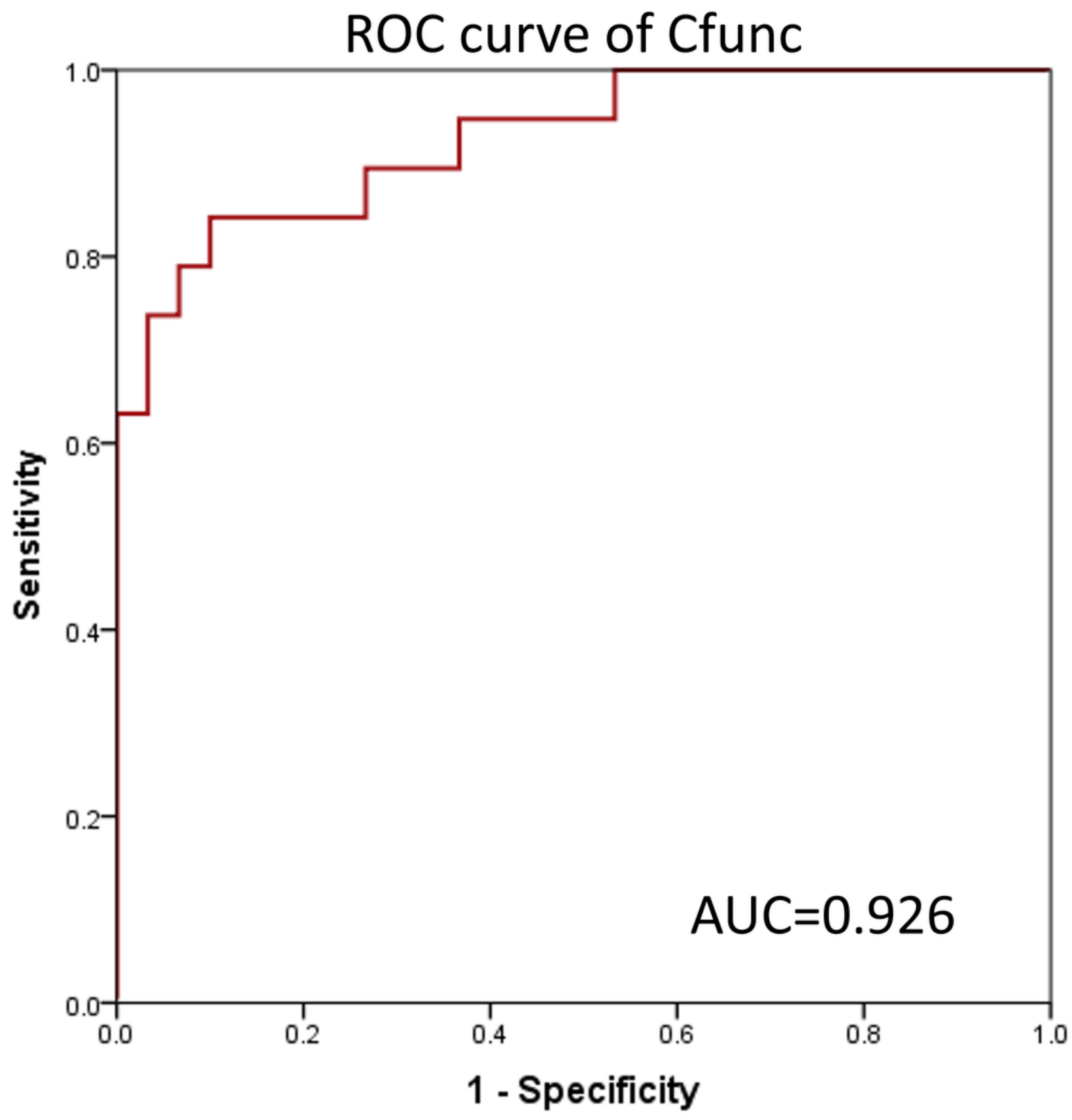


Figure 5

Results of multiple correspondence analysis.

(A) The correlation between the copy numbers of STR loci and IHC markers in GC and CRC.

(B) The correlation between the copy numbers of STR loci and tumor markers in GC and CRC.

GC, gastric cancer; CRC, colorectal cancer.
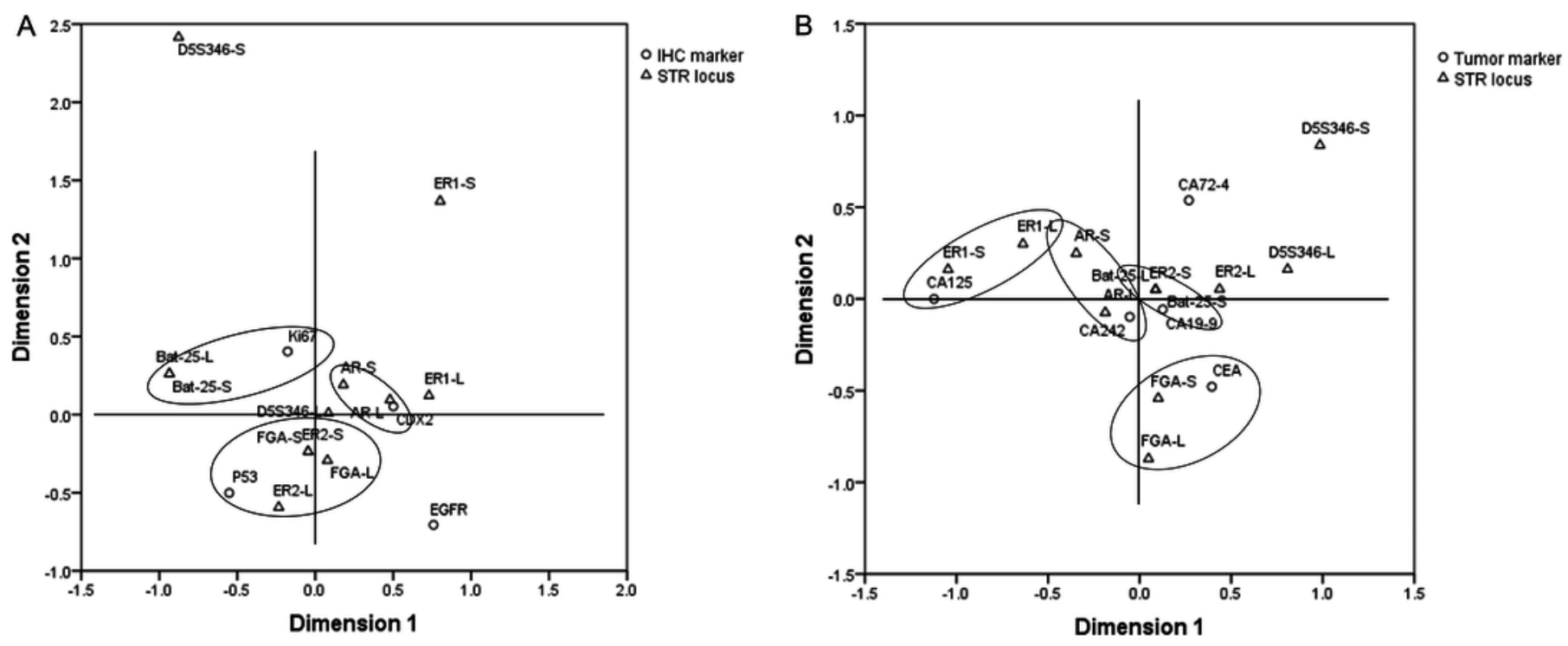


\section{Table 1 (on next page)}

Clinicopathological characteristics of the patients. 


\section{Table 1:}

2 Clinicopathological characteristics of the patients.

\begin{tabular}{|l|l|}
\hline Factor & $\begin{array}{l}\text { Gastrointestinal cancer }(\mathrm{n}=19), \\
\mathrm{n}(\%)\end{array}$ \\
\hline Age (years) & \\
\hline Mean \pm SD & $64.7 \pm 10.5$ \\
\hline Median & $64($ range, $46-88)$ \\
\hline$<60$ & $6(31.6)$ \\
\hline$\geq 60$ & $13(68.4)$ \\
\hline Sex & \\
\hline Male & $13(68.4)$ \\
\hline Female & $6(31.6)$ \\
\hline Location & \\
\hline Colon cancer & $6(31.6)$ \\
\hline Rectal cancer & $5(26.3)$ \\
\hline Gastric cancer & $8(42.1)$ \\
\hline Histological grade & \\
\hline I & $0(0.0)$ \\
\hline II & $11(57.9)$ \\
\hline III & $5(26.3)$ \\
\hline IV & $3(15.8)$ \\
\hline Nodal status & \\
\hline Positive & $11(57.9)$ \\
\hline Negative & $8(42.1)$ \\
\hline
\end{tabular}


Table 2 (on next page)

Characteristics of each STR marker.

Abbreviations: STR, short tandem repeat. 
1 Table 2:

2 Characteristics of each STR marker.

\begin{tabular}{|l|l|l|l|l|}
\hline STR marker & Position & Start Location & Repeat motifs & Gene \\
\hline AR & Xq12 & 66657655 & CAG & AR \\
\hline Bat-25 & $4 \mathrm{q} 12$ & 55633758 & T & C-kit \\
\hline D5S346 & $5 \mathrm{q} 21 / 22$ & 111646983 & GT & APC \\
\hline ER1 & $6 \mathrm{q} 25$ & 151806531 & TA & ESR1 \\
\hline ER2 & $14 \mathrm{q} 23$ & 64253561 & TG & ESR2 \\
\hline FGA & $4 \mathrm{q} 31$ & 154587748 & AAAG & FGA \\
\hline
\end{tabular}

3 Abbreviations: STR, short tandem repeat. 


\section{Table 3(on next page)}

Primer sequences used for PCR amplification.

Abbreviations: HEX, 5' hexachlorofluorescein; FAM, 5' carboxyfluorescein; ROX, 5' carboxy-X-rhodamine. 
1 Table 3:

2 Primer sequences used for PCR amplification.

\begin{tabular}{|l|l|l|l|}
\hline $\begin{array}{l}\text { STR } \\
\text { markers }\end{array}$ & Forward & Reverse & Dye \\
\hline AR & AGGGCTGGGAAGGGTCTA & GGAGAACCATCCTCACCCT & HEX \\
\hline Bat-25 & CGCCTCCAAGAATGTAAGTG & AACTCAAGTCTATGCTTCACCC & FAM \\
\hline D5S346 & GGTTTCCATTGTAGCATCTTG & GCCTGGTTGTTTCCGTAGTA & FAM \\
\hline ER1 & TCTGTTGGGTGTTTGGGATA & TTACATTGTCGGTCTGGTCC & ROX \\
\hline ER2 & ATCTCAGTCTCCCCAAGTGC & TCCTTCAAGATAACCACCGA & FAM \\
\hline FGA & $\begin{array}{l}\text { TCGGTTGTAGGTATTATCACG } \\
\text { G }\end{array}$ & TGCCCCATAGGTTTTGAACT & ROX \\
\hline
\end{tabular}

3 Abbreviations: HEX, 5' hexachlorofluorescein; FAM, 5' carboxyfluorescein; ROX, 5' carboxy-X4 rhodamine. 


\section{Table 4 (on next page)}

Formulas for calculating the copy number of each STR locus.

Abbreviations: $X$, the copy number of STR loci; S, the fragment length values of STR loci. 
1 Table 4:

2 Formulas for calculating the copy number of each STR locus.

\begin{tabular}{|l|l|}
\hline STR markers & Copy number $(\mathrm{X})$ \\
\hline AR & $\mathrm{X}=\operatorname{round}[(\mathrm{S}-191) / 3]$ \\
\hline Bat-25 & $\mathrm{X}=\operatorname{round}(\mathrm{S}-379)$ \\
\hline D5S346 & $\mathrm{X}=\operatorname{round}[(\mathrm{S}-202) / 2]$ \\
\hline ER1 & $\mathrm{X}=\operatorname{round}[(\mathrm{S}-359) / 2]$ \\
\hline ER2 & $\mathrm{X}=\operatorname{round}[(\mathrm{S}-278) / 2]$ \\
\hline FGA & $\mathrm{X}=\operatorname{round}[(\mathrm{S}-200) / 4]$ \\
\hline
\end{tabular}

3 Abbreviations: X, the copy number of STR loci; S, the fragment length values of STR loci. 


\section{Table 5 (on next page)}

The STR loci corresponding to X1-X12 in the discriminant formula . 
1 Table 5:

2 The STR loci corresponding to X1-X12 in the discriminant formula.

\begin{tabular}{|l|l|}
\hline Variables & STR loci \\
\hline X1 & AR-S \\
\hline X2 & AR-L \\
\hline X3 & Bat-25-S \\
\hline X4 & Bat-25-L \\
\hline X5 & D5S346-S \\
\hline X6 & D5S346-L \\
\hline X7 & ER1-S \\
\hline X8 & ER1-L \\
\hline X9 & ER2-S \\
\hline X10 & ER2-L \\
\hline X11 & FGA-S \\
\hline X12 & FGA-L \\
\hline
\end{tabular}




\section{Table 6(on next page)}

Result of cross-validation.

Abbreviations: GC, gastric cancer; CRC, colorectal cancer. 
1 Table 6:

2 Result of cross-validation.

\begin{tabular}{|l|l|l|}
\hline \multirow{2}{*}{ Actual } & \multicolumn{2}{|c|}{ Predicted(n, \%) } \\
\cline { 2 - 3 } & GC and CRC patients & Healthy controls \\
\hline GC and CRC patients & $14(73.7)$ & $5(26.3)$ \\
\hline Healthy controls & $7(23.3)$ & $23(76.7)$ \\
\hline
\end{tabular}

3 Abbreviations: GC, gastric cancer; CRC, colorectal cancer. 


\section{Table 7 (on next page)}

Coordinates of ROC curve for Cfunc and copy number of all STR loci.

Abbreviations: ROC, receiver operating characteristic; AUC, area under the ROC curve; STR, short tandem repeat. 
1 Table 7:

2 Coordinates of ROC curve for Cfunc and copy number of all STR loci.

\begin{tabular}{|l|l|l|l|l|}
\hline Method & \multirow{2}{*}{ AUC } & $\mathrm{P}$ & \multicolumn{2}{|c|}{ 95\%CI } \\
\cline { 4 - 5 } & & & Upper limits & Lower limits \\
\hline Cfunc & 0.926 & 0.000 & 0.851 & 1.000 \\
\hline AR-S & 0.479 & 0.806 & 0.312 & 0.646 \\
\hline AR-L & 0.332 & 0.050 & 0.180 & 0.484 \\
\hline Bat-25-S & 0.454 & 0.587 & 0.288 & 0.619 \\
\hline Bat-25-L & 0.430 & 0.412 & 0.264 & 0.595 \\
\hline D5S346-S & 0.894 & 0.000 & 0.771 & 1.000 \\
\hline D5S346-L & 0.798 & 0.000 & 0.674 & 0.923 \\
\hline ER1-S & 0.473 & 0.750 & 0.310 & 0.635 \\
\hline ER1-L & 0.622 & 0.154 & 0.465 & 0.779 \\
\hline ER2-S & 0.446 & 0.525 & 0.274 & 0.618 \\
\hline ER2-L & 0.305 & 0.023 & 0.150 & 0.461 \\
\hline FGA-S & 0.476 & 0.782 & 0.315 & 0.637 \\
\hline FGA-L & 0.582 & 0.335 & 0.419 & 0.746 \\
\hline
\end{tabular}

3 Abbreviations: ROC, receiver operating characteristic; AUC, area under the ROC curve; STR, short 4 tandem repeat. 